\title{
Prevalence and Clinical Correlates of Sexual Dysfunction among Primary Care Diabetes Mellitus Enrollees attending National Health Insurance Scheme (NHIS) Clinic in Uyo, South-South, Nigeria
}

\author{
Idung Alphonsus Udo ${ }^{1 *}$, Jombo Henry Effiong ${ }^{2}$, Iyanam Victory Edet ${ }^{1}$, Umoh Victor Aniedi ${ }^{3}$ \\ and Ekanem Anyiekere Morgan ${ }^{4}$ \\ ${ }^{1}$ Department of Family Medicine, Faculty of Clinical Sciences, College of Health Sciences, University of Uyo, Nigeria \\ ${ }^{2}$ Department of Mental Health, Faculty of Clinical Sciences, College of Health Sciences, University of Uyo, Nigeria \\ ${ }^{3}$ Department of Internal Medicine, Faculty of Clinical Sciences, College of Health Sciences, University of Uyo, Nigeria \\ ${ }^{4}$ Department of Community Health, Faculty of Clinical Sciences, College of Health Sciences, University of Uyo, Nigeria
}

*Corresponding author: Idung, Alphonsus Udo, Department of Family Medicine, Faculty of Clinical Sciences, College of Health

Sciences, University of Uyo, Akwa Ibom State, Nigeria

\section{ARTICLE INFO}

Received: 幽 July 04, 2019

Published: 慧 July 11, 2019

Citation: Idung Alphonsus Udo, Jombo Henry Effiong, Iyanam Victory Edet, Umoh Victor Aniedi, Ekanem Anyiekere Morgan. Prevalence and Clinical Correlates of Sexual Dysfunction among Primary Care Diabetes Mellitus Enrollees attending National Health Insurance Scheme (NHIS) Clinic in Uyo, SouthSouth, Nigeria. Biomed J Sci \& Tech Res 19(3)-2019. BJSTR. MS.ID.003318.

Keywords: Primary care; Diabetes mellitus; Female; Sexual dysfunction; NHIS clinic; South-South; Nigeria

\section{ABSTRACT}

Background: Female sexual dysfunction are disorders of sexual desire, arousal, orgasm and sexual pain which lead to significant personal distress. Female sexual dysfunctions though common are often under-reported.

Aim: The aim of this study was to describe the prevalence and clinical correlates of sexual dysfunction among female diabetes mellitus patients attending the National Health Insurance Scheme Clinic of a tertiary hospital in Uyo South-South Nigeria.

Method: In a cross-sectional study, 162 female diabetic patients were assessed for the prevalence of sexual dysfunction as well as affected domains of sexual function between January and June 2018. They were assessed using the female sexual function index (FSFI) questionnaire.

Results: A total of 108 (66.7\%) respondents had sexual dysfunction. The mean age at onset of diabetes mellitus among respondents with sexual dysfunction in this study was $43.6+6.1$ compared to $39.3+4.3$ among those without sexual dysfunction $(\mathrm{p}=0.04)$.

Forty-two $(77.8 \%)$ respondents with sexual dysfunction had neuropathy involving the extremities compared to $12(22.2 \%)$ without sexual dysfunction $(\mathrm{p}=0.050)$.

Twenty-five $(73.5 \%)$ respondents with sexual dysfunction were morbidly obese compared to nine $(26.5 \%)$ without sexual dysfunction $(\mathrm{p}=0.018)$.

The total FSFI score among respondents in this study was 22.6. Sexual pain was the most frequently experienced sexual dysfunction among respondents accounting for $93.5 \%$ (95\% cl 93.4-99.3), the least affected domain of sexual function among respondents in this study was sexual desire accounting for $72.2 \%$ (95\% cl $71.4-85.0$ )

Conclusion: Diabetes mellitus was associated with sexual dysfunction among respondents in this study. Primary care providers are encouraged to explore the presence of sexual dysfunction among female diabetic patients so as to offer adequate treatment and counselling as may be required.

\section{Introduction}

Sexual dysfunctions are disorders in sexual desire and in the psychophysiological changes that occur during the sexual response cycle [1]. Female sexual dysfunctions (FSD) are disorders of sexual desire, arousal, orgasm and sexual pain which lead to significant personal distress [2]. Good sexual and reproductive health and wellbeing are essential if people are to have responsible, safe and 
satisfying sex lives [3]. Female sexual dysfunctions though common are often under-reported [4]. Sexual dysfunction causes numerous deleterious effects on victims and their families such as loss of selfesteem, poor self-concept, mental stress, disorders in interpersonal relationships as well as problems with partners thus making sexual dysfunction a quality-of-life-issue [4,5]. Diabetes mellitus (DM) is a chronic metabolic disease caused by a variable combination of two pathogenic factors namely Insulin deficiency and Insulin resistance. It is characterized by high blood sugar (glucose) levels that result from defects in insulin secretion or its action, or both [6]. Elevated levels of glucose (hyperglycaemia) produce the classical symptoms of polyuria, polydipsia and polyphagia. In diabetes mellitus, there is disordered utilization and storage of proximate nutrients (carbohydrates, protein and fats) and reduced energy production.

Hyperglycaemia is its easily measured laboratory marker and the liability for chronic degenerative diseases in almost all body tissues. The mechanisms of sexual dysfunction among diabetes mellitus patients are complex and multifactorial and include both organic and psychological factors. According to report, Insulin resistance and the metabolic syndrome as well as visceral adiposity which are distinctive clinical traits of type 2 diabetes mellitus are associated with the development of sexual dysfunction especially in overweight and obese diabetic patients [7]. There has been increasing interest in research on sexual problems among individuals with diabetes mellitus in Nigeria [8-10]. Published reports on sexual dysfunction among female primary care diabetes mellitus National Health Insurance Scheme Clinic enrollees in Uyo, South-South Nigeria are rare in scientific literature. It is hoped that findings from this study will assist primary care providers to provide effective and evidence-based holistic care to the female diabetes mellitus patients.

\section{Subjects, Materials and Methods \\ Location of the Study}

The study was carried out at the National Health Insurance Scheme (NHIS) clinic of the University of Uyo Teaching Hospital (UUTH) between January and June 2018. Family medicine department of UUTH operates four clinics. These are the general out-patient clinic (GOPC), the federal staff clinic, the staff medical services clinic and the National Health Insurance Scheme (NHIS) clinic. The NHIS clinic caters for the health care needs of employees of various ministries, department and agencies (MDAs) of The Federal Government of Nigeria otherwise referred to as formal sector employees [11]. The clinic holds between $8.00 \mathrm{am}$ and $4.00 \mathrm{pm}$ every week from Monday to Friday excluding public holidays. The clinic attends to adult patients undifferentiated by gender, disease or organ system. About twelve thousand $(12,000)$ enrollees have registered with the NHIS scheme in UUTH.

The University of Uyo Teaching Hospital (UUTH) was established in 1996 as a state specialist Hospital before it was later taken over and renamed Federal medical centre (FMC) Uyo by the federal government of Nigeria. It was granted the status of a
Teaching Hospital in February 2007 by the Federal Government of Nigeria. UUTH is located on the outskirts of Uyo, the capital of Akwa Ibom State and has twenty-one (21) clinical departments including Family Medicine. It is a 600-bed hospital and occupies a land mass of 43 hectares and currently serve a population of about 4 million people of Akwa Ibom and neighboring states of Cross River, Abia and Rivers in South-South Nigeria [12]. Nigeria is divided into six geo-political zones as follows: North-East, North-West, South-East, South-West and South-South. The South-South geo-political zone is otherwise referred to as the Niger-Delta region. It is one of the major oils producing areas in Nigeria.

An average of 100 patients are treated in the NHIS clinic every day, thus about twelve thousand patients patronize the clinic in 6-months. About one thousand four hundred (1400) female diabetic patients were projected to attend the clinic during the period of study which was between January and June 2018. This projection followed unpublished record obtained from the Health records department of the hospital concerning the number of female diabetic patients who attended the clinic during the same period in the previous year. These comprised all newly registered patients as well as those who returned for follow-up care. A total of 162 female diabetic patients who attended the NHIS clinic between January and June 2018 were recruited for the study. Sample Size for this study was calculated using the formula $\mathrm{Z}^{2} \mathrm{pq} / \mathrm{d}^{2}$ where ' $\mathrm{N}$ ' is standard normal deviation set at $95 \%$ confidence level which corresponds to 1.96, ' $\mathrm{p}$ ' is the reported prevalence of sexual dysfunction among female diabetics (88.0\%)9, ' $d$ ' is the precision which at $95 \%$ confidence interval is $5 \%$.

The calculated sample size was 162 . They were sampled from the 1400 female diabetic patients who attended the clinic during the study period. They were recruited by systematic sampling method with a sampling interval of nine. Numbers ranging from one to nine were assigned to the first nine respondents who met the inclusion criteria. The first respondent was chosen by simple balloting which was done by randomly picking one of the numbers from a basket containing the assigned numbers. Thereafter every ninth (9th) respondent was recruited for the study. Their case notes were marked to forestall duplication of entry. Inclusion criteria included willingness to take part in the study as well as those aged between 18 years and above. Exclusion criteria included diabetic females who were pregnant, or those with emergency diabetic complications who needed urgent intervention as well as those who were below 18 years of age. Ethical approval for this study was obtained from UUTH institutional review committee. A pre-test of the research questionnaire was performed in order to determine its applicability, experience and logistic problems. This was a prospective cross-sectional study conducted between January and June 2018.

A semi-structured and pre-tested interviewer-administered questionnaire was used to obtain information about sociodemographic characteristics of the respondents such as age, marital status, highest level of education attained, income (in Nigeria 
Naira denomination) using the approved wage structure in the Nigerian public service [13]. Weight of respondents was measured in kilograms $(\mathrm{kg})$ to the nearest $0.5 \mathrm{~kg}$ using a hanna-calibrated bathroom scale, model BR 9011. Each subject was weighed wearing light clothing without shoes or stocking. The height of each subject was measured using an improvised wooden stadiometer mounted on vertical wall with the respondent standing erect against the wall on a horizontal floor without shoes. The head was placed so as to ensure that the external auditory meatus and the angle of the eye were on a horizontal line. The height was measured in meters to the nearest $0.1 \mathrm{~cm}$. Body mass index (BMI) was calculated [14]. Normal weight was defined as BMI of $18.0-24.9 \mathrm{~kg} / \mathrm{m} 2$, overweight as BMI of $25.0-29.9 \mathrm{~kg} / \mathrm{m} 2$ while obesity was defined as BMI of $>30.0 \mathrm{~kg} /$ $\mathrm{m} 2[15,16]$.

Diabetes mellitus was diagnosed based on the 2011 revised criteria of the expert committee on the diagnosis and classification of diabetes mellitus which recommends the diagnosis of diabetes mellitus based on two fasting plasma glucose (2FPG) levels of 126 $\mathrm{mg} / \mathrm{dl}(7.0 \mathrm{mmmol} / \mathrm{l})$ or higher or two 2-hours post prandial glucose 2-hppg reading of $200 \mathrm{mgldl}(11.1 \mathrm{mmol} / \mathrm{l})$ or higher or glycosylated Hemoglobin (HbAIc) of $>6.4 \%$. Blood sugar was considered to be poorly controlled if the glycosylated hemoglobin was $>6.4 \%$ at the time of enrollment for the study [17]. Body mass index and glycosylated hemoglobin were used to evaluate the metabolic profile of respondents. Nephropathy was diagnosed by increased urinary albumin excretion in the absence of other kidney diseases [18]. Neuropathy was diagnosed following American Academy of Neurology criteria [19]. Hypertension was defined as having a previous physician's diagnosis of hypertension or persistent elevation of Blood pressure of greater than 140/90 mmHg. Sexual dysfunction among the female respondents was assessed using the female sexual function index [FSFI] questionnaire. The FSFI is a brief 19-item self-report measure of female sexual function [20]. It was designed to assess the key dimensions of female sexual function in clinical practice.

The FSFI provides scores in six domains of sexual function namely desire, subjective arousal, lubrication, orgasm, satisfaction and pain [20]. Based on the Female sexual function index (FSFI), the range of score for sexual desire is $2-10$, a score of 2-4 denotes dysfunction in sexual desire while a score of 5-10 denotes no dysfunction; the range of score for sexual arousal is $0-20$, a score of Table 1: Characteristics of the study population.
0-10 denotes dysfunction in sexual arousal while a score of 11-20 means there is no dysfunction in sexual arousal; the range of score for vaginal lubrication is $0-20$, dysfunction is said to occur with a score of 0-10 while a score of 11-20 denotes no dysfunction with vaginal lubrication. The range of score for orgasm is $0-15$, a score of 0 -8 denotes orgasmic dysfunction, while a score of 9-15 means that there is no dysfunction with orgasm. The range of score for sexual satisfaction is 2-15, a score of 2-8 denotes dysfunction with sexual satisfaction while a score of 9-15 denotes no dysfunction. The range of score for sexual pain is $0-15$, a score of $0-10$ denotes the presence of sexual pain while a score of 11-15 denotes absence of sexual pain [8]. The female sexual function index has been used to study female sexual function in many countries including Nigeria [8-10,21-23].

\section{Data Analysis}

Statistical analysis was done using statistical package for social sciences (SPSS) version 21.0. Frequency distribution and cross tabulation were generated, chi-square was used to compare proportions. The corresponding $\mathrm{p}$-values were used to determine the level of statistical significance. The $p$-value of 0.05 was used to determine the level of statistical significance.

\section{Results}

One hundred and sixty-two (162) adult female diabetes mellitus patients were recruited for the study. The average age of respondents in this study was $32.4+5.3$ years. Respondents between the age bracket of $26-45$ years accounted for $67.9 \%$ of respondents. One hundred and one (62.3\%) respondents were married; $56.1 \%$ attained post-secondary level of education. Ninety (55.6\%) respondents were high level income earners; $77.8 \%$ lived in urban area while $66.0 \%$ were professionals in their chosen field of human endeavor (Table 1). Table 2 shows the clinical characteristics, treatment options as well as presence of complications among diabetic respondents with or without sexual dysfunction. The mean age at onset of diabetes mellitus among respondents with sexual dysfunction was $43.6+6.1$ compared to $39.3+4.3$ among those without sexual dysfunction. This was statistically significant $(\mathrm{p}=$ 0.04). Forty-eight (80.0\%) respondents with sexual dysfunction had suffered from diabetes mellitus for ten years and above compared to twelve [20.0\%] respondents without sexual dysfunction who also suffered from diabetes mellitus for the same duration and this was statistically significant $(\mathrm{p}=0.011)$.

\begin{tabular}{|c|c|c|}
\hline \multicolumn{2}{|c|}{ Fariables } & Age (in years) \\
\hline \multicolumn{2}{|c|}{ Percentage [\%] } \\
\hline $18-25$ & 21 & 13 \\
\hline $26-35$ & 68 & 42 \\
\hline $36-45$ & 42 & 25.9 \\
\hline $46-55$ & 19 & 11.7 \\
\hline $56+-$ & 12 & 7.4 \\
\hline & Marital Status & 9.9 \\
\hline
\end{tabular}




\begin{tabular}{|c|c|c|}
\hline Married & 101 & 62.3 \\
\hline Divorced/Separated & 27 & 16.7 \\
\hline Widowed & 18 & 11.1 \\
\hline \multicolumn{3}{|c|}{ Level of Education attained } \\
\hline No Formal Education & - & - \\
\hline Primary School & 9 & 5.6 \\
\hline Secondary School & 62 & 38.3 \\
\hline Post-Secondary School & 91 & 56.1 \\
\hline \multicolumn{3}{|c|}{ Level of Income } \\
\hline Low & 13 & 8 \\
\hline Middle & 59 & 36.4 \\
\hline High & 90 & 55.6 \\
\hline \multicolumn{3}{|c|}{ Place of Residence } \\
\hline Urban & 126 & 77.8 \\
\hline Rural & 36 & 22.2 \\
\hline \multicolumn{3}{|c|}{ Occupation } \\
\hline Semi- skilled & 21 & 13 \\
\hline Skilled & 34 & 21 \\
\hline Professionals & 107 & 66 \\
\hline
\end{tabular}

Table 2: Clinical characteristics, treatment options and complications among respondents with and without sexual dysfunction.

\begin{tabular}{|c|c|c|c|}
\hline \multirow{2}{*}{ Variables } & \multicolumn{3}{|c|}{ Respondents } \\
\hline & With sexual dysfunction $n[\%]$ & Without sexual dysfunction $n[\%]$ & p-value \\
\hline Mean age at onset of diabetes [years] & $43.6+6.1$ & $39.3+4.3$ & $0.004^{*}$ \\
\hline \multicolumn{4}{|c|}{ Duration of diabetes [years] } \\
\hline $1-5$ & $26[89.7]$ & $23[10.3]$ & \\
\hline $6-10$ & $34[64.2]$ & 19 [35.8] & $0.011^{*}$ \\
\hline$>10$ & $48.48[80.0]$ & $12[20.0]$ & \\
\hline \multicolumn{4}{|c|}{ Treatment for diabetes } \\
\hline Diet only & $7[43.8]$ & $9[56.2]$ & \\
\hline Injectables only & $21[63.6]$ & $12[36.4]$ & $0.006^{*}$ \\
\hline Injectables and oral medications & 19 [52.8] & $17[47.2]$ & \\
\hline Oral medications only & $61[79.2]$ & 16 [20.8] & \\
\hline \multicolumn{4}{|c|}{ Diabetes Complications } \\
\hline No complications & $45[57.7]$ & $33[42.3]$ & \\
\hline Nephropathy & $21[70.0]$ & $9[30.0]$ & $0.050^{*}$ \\
\hline Extremities Neuropathy & $42[77.8]$ & 12 [22.2] & \\
\hline \multicolumn{4}{|c|}{ Blood pressure levels (mmHg) } \\
\hline$<140 / 90$ & 50 [67.6] & $24[32.4]$ & 0.543 \\
\hline$>140 / 90$ & $58[65.9]$ & $34[34.1]$ & \\
\hline \multicolumn{4}{|c|}{ Laboratory Test (Glycated Hemoglobin (HbAIc) } \\
\hline$<6.4 \%$ & $64[62.7]$ & 38 [37.3] & 0.167 \\
\hline$>6.4 \%$ & 44 [73.3] & 16 [26.7] & \\
\hline \multicolumn{4}{|c|}{ Body mass Index (BMI) (kg.m²) } \\
\hline$<18.5$ & - & - & \\
\hline $18.5-24.9$ & $8[33.3]$ & $16[66.4]$ & \\
\hline $25.0-34.9$ & 19 [61.3] & 12 [38.7] & $0.018^{*}$ \\
\hline $35.0-39.9$ & 56 [76.7] & 17 [23.3] & \\
\hline$>40$ & 25 [73.5] & $9[26.5]$ & \\
\hline
\end{tabular}

${ }^{*}$ statistically significant 
Seven (43.8\%) respondents with sexual dysfunction used diet only to treat their diabetes mellitus compared to nine (56.2\%) respondents without sexual dysfunction. Sixty-one (79.2\%) respondents with sexual dysfunction used oral medications only to treat diabetes mellitus compared to sixteen $(20.8 \%)$ respondents without sexual dysfunction. This was statistically significant $(\mathrm{p}=0.006)$. Twenty-one $(70.0 \%)$ respondents with sexual dysfunction had nephropathy compared to nine $(30.0 \%)$ respondents without sexual dysfunction. Forty-two (77.8\%) respondents with sexual dysfunction had neuropathy involving the extremities compared to twelve $(22.2 \%)$ respondents without sexual dysfunction. This was statistically significant $(\mathrm{p}=0.050)$. Nineteen (61.3\%) respondents with sexual dysfunction were overweight compared to twelve (38.7\%) who were not. Twentyfive $(73.5 \%)$ respondents with sexual dysfunction were morbidly obese compared to nine (26.5\%) without sexual dysfunction. This was statistically significant $(\mathrm{p}=0.018)$.

Table 3 shows the prevalence of sexual dysfunction and the affected domains of sexual function among respondents in this study. The total FSFI score among respondents in this study was 22.6. The prevalence of sexual dysfunction among respondents in this study was $66.7 \%$. Sexual pain was the most frequently experienced sexual dysfunction among respondents accounting for $95.4 \%$, this was followed by lubrication dysfunction $93.5 \%$, dysfunction with orgasm $91.7 \%$ and sexual desire was the least, occurring in $72.2 \%$ of the respondents.

Table 3: Prevalence and impairment in domains of sexual dysfunction among respondents.

\begin{tabular}{|c|c|c|c|}
\hline Variables & Frequency (n) & Percentage [\%] & $95 \%$ CL \\
\hline \multicolumn{4}{|c|}{ Sex Dysfunction } \\
\hline Yes & 108 & 66.7 & $65.3-77.8$ \\
\hline No & 54 & 33.3 & \\
\hline \multicolumn{4}{|c|}{ Domains of Sexual dysfunction affected $*$} \\
\hline Desire & 78 & 72.2 & $71.4-85.0$ \\
\hline $\begin{array}{c}\text { Subjective } \\
\text { arousal }\end{array}$ & 98 & 90.7 & $84.3-94.4$ \\
\hline Lubrication & 101 & 93.5 & $87.5-96.4$ \\
\hline Orgasm & 99 & 91.7 & $88.6-95.7$ \\
\hline Satisfaction & 91 & 84.3 & $83.6-93.9$ \\
\hline Pain & 103 & 95.4 & $93.4-99.3$ \\
\hline
\end{tabular}

${ }^{*}$ multiple responses given

\section{Discussion}

Findings from this study show that sexual dysfunction was common among female respondents with diabetes mellitus. The prevalence of sexual dysfunction among respondents in this study was $66.7 \%$. This is high compared to the prevalence of $6.6 \%$ earlier reported among patients attending diabetes clinic of a teaching hospital in Benin City, South - South Nigeria. It is, however, comparable to the prevalence of $77.5 \%$ reported among female diabetic patients attending a general outpatient specialist clinic in Lafia, North-Central Nigeria.

It is higher than the prevalence of $53.5 \%$ reported among female respondents in a university community in Enugu, SouthEast Nigeria. The differences in the reported prevalence rates among different workers might be due to differences in the study design as well as the population studied. Whatever might be the reason, it is important to note that sexual dysfunction is common among women with diabetes mellitus due perhaps to organic impairment or fears arising from non-acceptance of the disease condition $[8,10,24]$.

Duration of diabetes mellitus as well as the presence of its complications were significant contributors to sexual dysfunction among respondents in this study. This is in agreement with reports from other studies. [25,26]. Sexual dysfunction occurs among diabetes mellitus patients due to metabolic and neurovascular factors that occur frequently among diabetics. Increase in body mass index (BMI) significantly contributed to sexual dysfunction among respondents in this study. This finding should, however, be interpreted with caution since large body frame in itself is a risk factor for many other health problems including sexual dysfunction. Pain was the commonest sexual dysfunction among respondents in this study. This is in agreement with reports from other studies $[8,27]$. Many reasons have been given by various workers and these include the fact that hyperglycaemia among diabetic women reduces hydration of the vaginal mucus membrane resulting in poor vaginal lubrication thus leading to sexual pain dysfunction [28]. It is further reported that clinically silent vaginal inflammation occurs very frequently in diabetic women thus giving rise to pain during sexual intercourse.

\section{Conclusion}

In conclusion, our study shows that diabetes mellitus is associated with sexual dysfunction. Primary care givers should explore the presence of sexual dysfunction among female diabetic patients with a view to addressing this issue during consultations so as to offer adequate treatment and counselling as may be required. This is particularly important since sexual dysfunction can exert a huge psychological burden on the patient with consequent negative impact on the marital relationship, family and quality of life of the patient. The limitation of this study is that potential confounders such as psychogenic factors and blood pressure medications were not addressed in this study. Moreover, because of lack of facilities it was impossible to characterize the respondents into type 1 or type 2 diabetics.

\section{References}

1. (2013) Diagnostic and statistical manual disorders. $5^{\text {th }}$ Edition. Arlington VA: American psychiatric Association p. 18

2. Basson R, Berman J, Burnett A, Derogratis L, Ferguson D, et al. (2000) Report of the International Consensus development conference on 
female sexual dysfunction: definitions and classifications. The Journal of urology 163(3): 888-893.

3. (2006) World Health Organization. Defining Sexual Health: Report of technical consultation on sexual health. Geneva.

4. Philips NA (2000) Female Sexual dysfunction: evaluation and treatment. American Family physician 62(1): 127-148.

5. Elyasi F, Kashi Z, Tasfieh B, Bahar A, Khadem Loo M (2015) Sexual dysfunction in women with type 2 diabetes mellitus. Iranian Journal of Medical Sciences 40(3): 206 -213.

6. (2010) Definition, Diagnosis, and Classification of diabetes mellitus. World Health Organization. Diabetes care 33 (supplement 1): S62-S69.

7. Maiorino MI, Bellastella G, Esposito K (2014) Diabetes and sexual dysfunction: Current perspectives. Diabetes metab Synd Obes 7: 95-105.

8. Unadike BC, Eregie A, Ohwovoriole AE (2009) Prevalence and types of sexual dysfunction amongst female with diabetes mellitus. Pak J Med Sc 25(2): 257-260.

9. Ogbera A0, Chinenye S, Akinlade A, Eregie A, Awobosuyi J (2009) Frequency and correlates of sexual dysfunction in women with diabetes mellitus. The Journal of Sexual medicine 6(12): 3401-3406.

10. Amanyam CT, Yohanna S, Obilom RE (2016) Assessment of sexual dysfunction in patients with diabetes mellitus in the general out-patient of Dalhatu Araf specialist Hospital, Lafia. Nigeria. Journal of Family Practice 7(3): 35-42.

11. Obalum DC, Fiberesima F (2012) Nigerian National Health Insurance Scheme (NHIS): an overview. The Nigerian Postgraduate Journal 19(3): 167-174.

12. (2007) Quarterly Bulletin of the World Health Organization, Abuja, Nigeria 18(1): 7.

13. (2011) National Minimum Wage Act Cap No.61 Laws of the Federation of Nigeria 2004.

14. Garrew JS, Webster J (1985) Quetelets' Index (W/H2) as a measure of fatness. Intl J Obes 9(2): 142-153.

15. (2005) Preventing Chronic diseases: A vital investment. Geneva: World Health Organization.

16. Njoku CH (2006) Obesity measurement and management: a review. Nigerian Medical Practitioner 49(6): 144-147.

\section{ISSN: 2574-1241}

DOI: 10.26717/BJSTR.2019.19.003318

Idung Alphonsus Udo. Biomed J Sci \& Tech Res

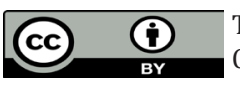

This work is licensed under Creative

Commons Attribution 4.0 License

Submission Link: https://biomedres.us/submit-manuscript.php
17. (2011) International Diabetes Federation (IDF). $5^{\text {th }}$ Edition of the diabetes Atlas.

18. American Diabetes Association (2004) Nephropathy in diabetes. Diabetes care 27 (suppl1): S79-S83.

19. England JD, Gronseth GS, Franklin G, Miller RG, Asbury AK, et al. (2005) Distal symmetric polyneuropathy: A definition for clinical research Report of the American Academy of Neurology, the American Association of Electrodiagnostic medicine and the American Academy of physical medicine and rehabilitation. Neurology 64(2): 199-207.

20. Rosen R, Brown C, Heiman J, Leiblum S, Meston C, et al. (2006) The female sexual function index (FSFI): a multi-dimensional self-report instrument for the assessment of female sexual function. J Sex marital ther 26(2): 191-208.

21. Giraldi A, Kristensen E (2010) Sexual dysfunction in women with diabetes mellitus. Journal of sex research 47(2): 199-211.

22. Ali RM, Al Hajeri RM, Khader YS, Shegem NS, Ajlouni KM (2008) Sexual dysfunction in Jordanian diabetic women. Diabetes care 31(8): 15801581.

23. Wiegel M, Meston C, Rosen R (2005) The Female Sexual Function index (FSFI): Cross-validation and development of Clinical cut off scores. J Sex Marital Therapy 31(1): 1-20.

24. UI Nwagha, TC Oguanuo, K Ekwuazi, TO Olubobokun, TU Nwagha, AK (2014) Prevalence of Sexual dysfunction among Females in a university community in Enugu, Nigeria. clinical practice 17(6): 791-796.

25. Ungaya Likata GM, Kuria MW, Olando Y, Owiti FR (2012) Sexual dysfunction among patients with diabetes mellitus. Greener Journal of Medical Sciences 2(6): 138 -145.

26. Mazilli R, Imbrogno N, Elia J, Delfino M. Bitterman O, et al. (2015) Sexual dysfunction in diabetic women. prevalence and differences in type I and type 2 diabetes mellitus. Diabetes metab Synd Obes 8: 97-101.

27. Bargiota A, Dimitropoulos K, Tzortzis V, Koukoulis GN (2011) Sexual dysfunction in diabetic women. Hormones 10(3): 196-206.

28. Erol B, Tefekli A, Ozbey I, Salman F, Dincag N, et al. (2002) Sexual dysfunction in type II diabetic females: a comparative study.J Sex marital Ther 28 (Suppl 1): 55-62.

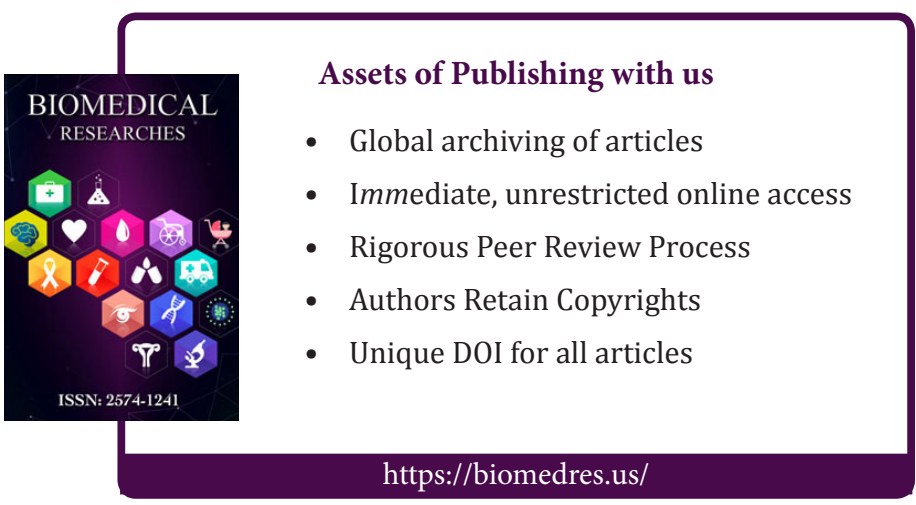

Copyright@ Idung Alphonsus Udo | Biomed J Sci \& Tech Res | BJSTR. MS.ID.003318. 